ARTICLE

Received 21 Jun 2016 | Accepted 26 Aug 2016 | Published 27 Sep 2016

\title{
Integrity and its counterfeits: Shakespeare's Henriad
}

\author{
Simon Robinson ${ }^{1}$
}

ABSTRACT The article will briefly and critically review philosophical views on integrity, focusing on integration, identity, standing up for moral principles and ethical decision-making practice. It will explore integrity as Aristotle's virtue of truthfulness, noting how this leads to engagement with the self and the social network. This demands the practice of responsibility, involving: critical agency (developing authorship of the ethical narrative), accountability (involving plural and mutual dialogue), and creative (positive) responsibility (involving both narrative and dialogue around action). In light of this dynamic and social view of integrity the second part the article explores counterfeit integrity. It distinguishes counterfeit integrity based in unexamined ideology and identity from counterfeit integrity based in intentional deception of others about beliefs, values and motives. Each of these is illustrated by figures from Shakespeare's Henriad, and parallel cases in business and sport. This article is published as part of a collection on integrity and its counterfeits.

\footnotetext{
${ }^{1}$ Leeds Beckett University, West Yorkshire, UK Correspondence: (email: s.j.robinson@leedsbeckett.ac.uk)
} 


\section{Philosophical perspectives of integrity}

$t$ is surprising that there is little detailed work on integrity from Greek philosophy or the Judaeo-Christian tradition (Cottingham, 2010). Recent work tends to stress the integrity as either a super virtue or a virtue which connects with other virtues (Palanski and Yammarino, 2007; Solomon, 2007, 1984; Scherkoske, 2013). This can be viewed under four connected heads: self-integration; identity; sustaining moral purpose; and commitment.

Self-integration. This account of integrity suggests the integration of what Frankfurt (1971) refers to as higher order or lower order volitions. Higher order volitions involve long-term desires, and lower order volitions immediate desires. The higher order volition of the drug addict, for instance, may be to be a drug-free person and the lower order volition to take drugs. Integrity, and with that free will, argues Frankfurt, is achieved when the lower order volitions cohere with the higher order volitions, bringing together volition and action, coming together in a committed decision. Self-integration can also been seen in terms of developing a holistic integration of the self that brings together the cognitive, affective and somatic aspects of the person (Solomon, 2007).

Identity. Williams (1973) argues for a view of integrity based in the identity of the person. This is part of his argument against a simple utilitarian approach. One example that he offers is of a dignitary who is the guest of a foreign nation. He is taken to a town square where 20 people are about to be killed as reprisals for recent armed protests. As a significant guest the visitor is offered the opportunity to kill one of the 20 , thus allowing the other 19 to live. A utilitarian response might support this based on the saving of 19 lives. In arguing against this, Williams claims that such a calculation is inadequate because it involves going against the core moral beliefs that make up the identity of the person.

Moral purpose. Rawls (1972) and Halfon (1989) argue that integrity must include an acceptable moral purpose at the base. For Rawls this would involve some clear conception of justice, defined in terms of fairness. Halfon is more circumspect, arguing that integrity involves setting out an ethical perspective that is conceptually clear, logically consistent, apprised of relevant empirical evidence, and careful about acknowledging as well as weighing relevant moral considerations. In effect, Halfon argues that the person of integrity will give a clear account of their moral purpose as part of following a rigorous moral decision-making process.

Commitment. Calhoun (1995) argues for a sense of commitment which is about "standing for something". She argues that this involves more than simply standing for an individual moral purpose, but rather for a purpose recognized by some community, which affords the basis for integrity. Integrity here is associated explicitly with something worth striving for, and it assumes a degree of agency, courage and perseverance that will enable the person or group to stand up against internal and societal pressures that impose obstacles to the purpose. The concern for the practice of rational agency, for taking responsibility for holding certain values, is echoed by Mason (2001). He argues for the importance of respect for human dignity as a core community principle. In all this integrity becomes more a social value than an individual one.

Each of these approaches have had problems which focus around critical agency and shared moral meaning. It is possible for the SS guard to claim integrity precisely because he claims integration of the self, a moral purpose (along with underlying worldview), and a strong commitment (see Burleigh, 2011). Integrity then has to take account of criticality, that is, the capacity to critique moral purpose, identity and so on, and complexity, that is, the presence of many different moral narratives, which claim the moral high ground. Not surprisingly then Halfon and Calhoun, among others, want to see the practice of moral decision-making as a key element of integrity, a sort of moral transparency. The problem with that is that we need to agree on what this "process" of moral transparency might be, and how we balance that with moral content.

Audi and Murphy's (2006) way around this is to simply accept that integrity has no contribution to moral content. It is to do with the process, and thus important, but secondary. Intuitively, this seems problematic. Whatever meaning we take integrity to have it is something which is prized. It less a handmaid to moral content, and more something about the self. This can be expressed in the argument that moral decision-making is much more than a rational reflection on moral concepts. Submerged beneath the "decision-making" are psychological and social relationships which connect to different value narratives and worldviews (Robinson, 2008). How we handle those relationships is precisely what integrity involves. This is partly why integrity has to focus on major principles, such as respect and freedom. These are core conditions of relationships. For these and other reasons Scherkoske (2013) wants to refocus integrity as an epistemic virtue. This precisely enables us to stand back and view the complexity of a situation, along with the many different value narratives, internal and external to the self. In that light, it is as much about consciousness of the social and physical environment as it is about a critical stance on values, moral or broader. Robinson and Smith (2014) attempt to bring together the several different aspects of these views into a view of integrity which includes:

Integration. Of the different parts of the person: emotional, psychological and intellectual. This leads to holistic thinking, and an awareness of the self, alongside awareness and appreciation of external data.

Consistency. Between the self, values and practice; past present and future; and different relationships, situations and contexts. Integrity is tested most of all in the relationship with stakeholders, who may have very different claims and perceived needs. This demands a consistency of approach, with a clarity about core values, and capacity to develop dialogue. The response may not be exactly the same in every context, but will remain consistent to the identity and purpose of the person of the organization. Central to this is the idea of being true to purpose and identity, requiring the practice of phronesis or practical wisdom.

Honesty and transparency: Involving an openness to the self and others. This raises many questions about the basis of this openness.

Independence. This is a key element of integrity. It ensures distance, such that the professional can stand apart from competing interests, and more effectively focus on the core purpose, enabling professional autonomy.

Learning process. Given the limitations of human beings, it is impossible to have complete integrity in any static sense. Hence, integrity is best viewed in terms of a continual learning process, with the person discovering more about the different aspects of the self and others and how these connect. Central to this is the capacity to reflect, to evaluate practice, to be able to cope with 
criticism and to maintain, develop or alter practice appropriately. Hence, integrity is focused in relationships, and is not purely individualistic.

Commitment. To purpose, project and people over time, and to the common good. The narrow view of integrity within a closed system has to be tested against fundamental principles such as justice.

In response to such integrative approaches Curzer (2014) hangs back. He argues for a simpler view, based in Aristotle's virtue of truthfulness (alètheia). This personal virtue involves representing oneself accurately and reliably to others. The self is seen as one's history, one's current character, and one's future projects, and expressed in one's commitments (to ideals, values, goals, projects), especially about those that are important to one's reputation. This is not a meta-virtue (cf. Solomon, 2007), connecting many other virtues such as honesty, transparency or authenticity, but a discrete virtue focused in being true to the self, one's identity. The simplicity of this is appealing. However, there are two immediate problems. First, it attempts to solve the problems around integrity simply by reframing the meaning, not least by not including self-knowledge in integrity. Self-knowledge is simply located as a different virtue (megalopsychia) which includes greatness. The issue of self-knowledge, however, does not go away and Cottingham (2010) argues that if integrity is about truthfulness and the self, it must involve engagement with the complex self and thus ongoing development of self-knowledge. Second, as Curzer (2014) himself concedes, the self is not univocal, but is made up of several different narratives which relate to the different relationships, historical and contemporary. ${ }^{1}$ This takes integrity down a difficult and complex journey involving the process of engaging with the self. It also means that the Aristotelian view of integrity, attractive though it is in stressing the relationship between the inner and outer, or projected, self, cannot be viewed simply in terms of consistency between identity, values and practice. By definition the self that is made up of different narratives (Cooper-White, 2007; Burkitt, 2008) also involves different associated relationships and thus is constituted through the practice of those relationships, which involves the interrogation of the related narratives. The very fact that that there are different narratives demands such interrogation to make sense of the self.

\section{Developing integrity}

Integrity is not then about wholeness as homogeneity, with everything fitting together, but about an honest and open engagement with the different narratives which make up the identity of the person (Bakhtin, 1984; Burkitt, 2008; Hermans, 2012), subjecting them to critical challenge. The different narratives are related to different formative relationships, which also have to be engaged with respect. In this light, integrity involves hard work and even struggle (Cottingham, 2010; Pianalto, 2012) and involves recognition of contradictions and inconsistencies in the self. Often psychological pathology emerges precisely when narratives, for whatever reason, are suppressed or ignored (Cooper-White, 2007). All of this has discernible effect on how the person views him or herself and the world. It is not surprising then that unresolved psychological problems might reinforce any "blindness" in this. Jung (1938) views such blindness in terms of a shadow side (Beeb and Rosen, 2005; cf. Cottingham, 2010; Fawkes, 2014). This is not a "dark" side but rather simply the part of our behaviour or thinking we choose, at whatever level, not to examine.

What constitutes identity, and with that a sense of the self, is not simply decision-making (Taylor, 1989; Korsgaard, 2009; Cottingham, 2010), but the practice of narrative and dialogue
(Burkitt, 2008) and with that the commitment to process people and projects. Narrative, as Ricoeur (2000) argues, develops the authorship of the person or organization. In effect this is taking responsibility for meaning and practice (cf. Calhoun, 1995). Part of this involves distanciation (van der Ven, 1998, Freeman, 2015) enabling awareness of the self and the different elements of the self (cf. Scherkoske, 2013), and part involves commitment to the self over time.

Dialogue involves the communication of this self to others, hence the dialogic and social self (Bakhtin, 1984; Sidorkin, 1999; Ricoeur, 2000; Burkitt, 2008). This also involves distanciation, enabling ongoing learning about the self in relation to the social network. This also suggests that integrity is essentially social. Consciousness of the self demands the perspective of others, both in the self and beyond. Hence, Ricoeur (2000) writes of the self as another. Such a dynamic view of integrity develops Calhoun's view of integrity as focused in taking responsibility.

Responsibility involves three modes, attributability, focused in critical agency, accountability and positive responsibility (Robinson, 2009). The first involves taking responsibility for critical engagement with core values, purpose, sense of worth, and practice and its effect on the social and cultural environment. This is core to the development of autonomous agency (Taylor, 1989), and thus to the development of identity in relationship. This involves owning authorship. In narrative identity, the person is not merely the one who tells the story, or merely the one about whom the story is told, but she "appears both as a reader and the writer of its own life" (Ricoeur, 1987: 246). Thus, the individual is both the interpreter and the interpreted, as well as the recipient of the interpretations. This enables awareness of otherness, of the social and physical environment and of the self as another. This is close both to the idea of meta-cognition (Flavell, 1987), the ability to reflect on how we think, and mindfulness (Miller, 2003), awareness of oneself in relation.

Accountability involves taking responsibility for giving an account of this identity to the self/organization and others. Focused in ongoing critical dialogue this enables a continual testing of the "shadow" side, and further presentation and development of the self-identity (Robinson, 2009). Positive responsibility demands a shared responsibility for maintaining both the re-presentation of core values and purpose, and harmony among the different narratives, including the sustainability of the self/organization and the core values. Such shared responsibility demands ongoing critical dialogue about purpose and creative response, and the negotiation of responsibility, further representing and establishing identity (Ricoeur, 2000). Ultimately, this moves to an opening out and testing of universal responsibility, in the sense of shared responsibility for the self and others (cf. Jonas, 1984; Arendt, 1991).

All this applies to both personal and organizational integrity. Just as the person may be said to be plural, the organization, institution or corporation may be said to be plural (Robinson, 2009). Far from having a single identity the corporation relates to different professions, some part of all corporations, such as accountancy and human relations, some related to the nature of the corporation, such as engineering. Brown (2005) develops this theme for corporations, noting five dimensions of corporate integrity-cultural, interpersonal, organizational, social and natural. The first focuses on difference and disagreement in meaning, the second integration and wholeness, the third core purpose, the fourth on civic cooperation, and the final on the environment. Integrity in this light demands both commitment to core relationships, but also awareness and appreciation of the plurality of relationships that form the social and physical environment. Such relationships are by definition interdependent, and integrity demands a working through of what that requires in 
practice (Koehn, 2005). Organizational integrity in the light of this once more requires both attention to dialogue, but also to shared narrative such as justice, or about the nature or purpose of the organization (Khurana and Nohria, 2008). The issue of organizational justice relates precisely to procedural integrity. Here procedures need to embody a shared understanding of justice and of the core purpose of the organization.

Four things may be added to this. First, this dynamic view of integrity connects what are often seen as different kinds of integrity, such as personal, professional, procedural (organizational) and political (in an inclusive sense) (cf. Bauman, 2013). Identity based in plural dialogue and the development of narrative precisely involves all of these. Second, while this view of integrity involves moral meaning it cannot be viewed as exclusively a moral concept. On the contrary, integrity involves the practice of intellectual virtues, such as practical wisdom (phronesis, the reflection on the good and its embodiment), relational/psychological virtues such as empathy, as well as moral virtues, such as justice. Third, the practice of responsibility then is what holds together the different virtues, exemplified in the development of dialogue and narrative (cf. Robinson, 2016). This is slightly different from the view that integrity is either a super virtue, connecting all of the virtues (Solomon, 2007), or simply an epistemic virtue (cf. Flavell, 1987; Scherkoske, 2013). It is the practice of responsibility in its three modes, mediated through dialogue, which involves the virtues: critical agency focusing on the practice of phronesis; accountability focusing on the practice of empathy, courage and justice; positive responsibility focusing on phronesis and creative virtues, including courage and imagination. Finally, such a view of integrity demands more than simply the development of systems of internal and external regulation to guard against corrupt practices. The danger of such regulation is precisely that it avoids taking responsibility for value and practice. I will return to this as a form of counterfeit integrity.

\section{Counterfeit integrity}

The language of counterfeit with regard to integrity is important. Counterfeit literally means imitation. Imitation is not per se false or morally wrong. On the contrary, imitation is critical to social learning and healthy sensorimotor development. New behaviours are acquired via imitation. Imitation assists in communication, social interaction, and even the ability to modulate one's emotions to account for the emotions of others (Gergely and Csibra, 2005). In one sense then it is possible to see imitation as being involved in integrity as a learning process, not least through the development of empathy. It is less easy to see a positive view of imitation in relation to integrity as a whole. This is principally because integrity, as argued above, is focused in critical thinking and thus demands that responsibility is taken for that thinking, decision-making, accounting and related practice. Imitation of behaviours or attitudes precisely tends to avoid such ownership of thinking and practice. There may be very different reasons for this.

First, integrity might be viewed precisely as non-thinking adherence to values or ideology. This may involve unintended self-deception, but no intentional deception of others at personal or organizational level. Second, perceived integrity may be based in a strong sense of identity, and the felt need to maintain reputation. Like the first there may be no intentional attempt to deceive as such. Nonetheless, such integrity is not genuine precisely because it involves both lack of critical thinking and lack of awareness of the social and physical environment.

Third, there may be intentional re-presentation of the self as morally good whilst practising the opposite. Here intended counterfeit is a key part of corruption, involving attempts to benefit from deception, and the presentation of integrity is there to disguise this behaviour. Counterfeit integrity in this sense might be termed the instrumental re-presentation of the self. In other words, integrity is presented primarily to pursue the narrow interests of the person or organization (Cox et al., 1999).

Broadly then, the first two of these involve unintended deception and the second involves intended deception. We should not be surprised about the extent of counterfeit integrity. At one level there are strong motivations based in self-interest. Some argue that this provides the basis of trust which is essential to relationships which further particular interests, such as business relationships (Forrest and O'Rourke 2015). At a psychological level there are at least two motivations. First, Festinger (1962) notes the strong desire to be seen as acceptable. Jung writes about this in terms of the development of the persona. The persona is in effect a mask that projects an acceptable social image, while also concealing "the true nature of the individual" (Jung, 1953: 190). It is important to have a flexible persona to project a sense of the self (cf. Goffman, 1956). The danger is that the self is identified completely with the persona, leading to high conformism, and lack of critical thinking or social awareness of the self as distinct from the world. Second, and related, there is a strong motivation to avoid responsibility for recognizing and responding to complexity, not least when a complex set of narratives, internal and external, are related to challenging emotions (Cooper-White, 2007).

I will use three examples of leadership to explore these kinds of counterfeit integrity taken from key figures in Shakespeare's Henriad, the series of plays that charts kingship from Richard II, through Henry IV pt. I and 2, and Henry V, and add related case studies.

\section{Richard II}

From the age of 10 Richard II was steeped in the core myth of Christian kingship. Founded in the Judeo Christian faith and reinforced by neo-Platonism this portrayed the king as being divinely appointed and atop the human section of the Great Chain of Being (Lovejoy, 1964). For Richard, the core religious meaning of his position effectively dominated his leadership, and was directly connected to the use of reward and punishment. Hence, for instance, Richard speedily banishes his cousin Bolingbroke despite his innocence. There is little attention in his leadership to relationships, or any attempt to be accountable for actions. The ideology of kingship dominates all, and provides the basis of the practice of "integrity".

The result is that Richard is literally unaware of the other, inside or outside the court, and, with that, unaware of different meaning associated with internal and external relationships. A good example of this is the meaning of justice, which he associates only with the right of kings. Justice for him is centred in the power and need of the king, with all else a means to that end, and all ethics and responsibility limited to this perspective. Hence, within minutes of his uncle John of Gaunt's death Richard sees this as an opportunity to seize all of his resources for the Irish campaign (Richard II, 2.1). York appeals to justice and family ties, but Richard does not seem to comprehend this, simply repeating the command to seize the goods. As a result the culture of the court is, for the most part, monological, focused in one voice and one meaning. If meaning is defined exclusively in terms of divine kingship then by definition there cannot be different, still less challenging, views. When challenge does come from Bolingbroke, Richard is still unable to understand an idea of justice that transcends the authority of the king, and thus can only view Bolingbroke's return as an attack on the divine right of king's. Hence, on return from Ireland he calls for an army of angels to 
match and meet the troops of Bolingbroke (Richard II, 3.2, 55), reinforcing the sense of Richard's unreal perception.

Integrity then for Richard involved the imposition of ideology and related behaviours. Precisely because of this there was a breakdown of reality, involving:

- Dissociation. The term involves a spectrum of detachment, from immediate surroundings, to, more severe, from physical and emotional experience (Cooper-White, 2007). Dissociative behaviour involves a detachment from reality, something which has similarities to psychosis, in which reality is lost (Callender, 2010).

- Projection. This psychological theory (Callender, 2010) suggests that individuals defend themselves against difficult impulses through denying them in themselves and attributing them to others. Hence, someone who feels anger might project this anger on to others, accusing them of bullying, rudeness and so on. Typically such leaders will characterize others as aggressive, leading to,

- Polarization. This involves polarizing ideas and groups, focusing on a defensive stance against other groups (Cohen, 2001). Thinking in these cases inevitably moves to ad hominem arguments, focused in the person of the opponent not the issue at question.

- Denial of responsibility. As Bauman (1989) notes this leads of denial of responsibility and shifting of blame (cf. Cohen, 2001). This is characteristic of people and organizations who are unable to capture plurality as part of their identity, or who operate in fragmented parts of their lives. As Ricoeur (2000) notes this is less about engagement and more about defence of the person or organization. The result of this in organizations is a culture of fear.

- Denial of people and practice, or their significance. A key effect of this is on perception, both of phenomena and of the significance of phenomena. The leader may see effects in the social networks, but simply not understand their significance. Typically this will lead to the "other" as being dehumanized.

In Richard's case there is a monovocal identity and the absence of any of the three modes of responsibility. Richard's perception is, of course, tested by the subsequent meetings, both in the battlefield and the court. And as Richard lets go of his authority and power, he reflects at length on his identity, beginning to see himself as a human being apart from his identity as leader (IV, 1). In Jungian terms this involves the breakdown or disintegration of the persona (cf. Homans, 1995: 100-102). Typically for Shakespeare there is ambiguity. This can be seen either as Richard's gradual disintegration or as his discovery of his real self, something remarkable in the light of the culture of the time (IV, $1, \mathrm{~V}, 5)$. Either way, Richard as a leader is unable to balance meaning, identity, and relationships, which resulted in him abusing his power. There is no persuasion, only coercion. There is no awareness of limitations, or awareness of the social environment or its significance. The central myth is unquestioned and unquestionable, and meaning beyond that, such as universal ideas of justice not understood. Articulation of the ideology and identity is rehearsed with no practice of genuine dialogue.

Similar ideological dominance was there with Alan Greenspan who was central to the credit crisis (Heffernan, 2012). Underlying Greenspan's values was a belief in negative freedom, that is, freedom from coercion (Berlin, 1968). His world view was deeply influenced by the philosophy of Rand. Rand's, (1992: 1170-1171) objectivist philosophy was summed up by her as, "the concept of man as a heroic being, with his own happiness as the moral purpose of his life, with productive achievement as his noblest activity, and reason as his only absolute". The individualized base of this philosophy suggests little connection to the wider society or environment, and certainly no sense of responsibility. Even more problematic is the view of reason as an absolute, denying the role of the affect. Parallel with this was an almost mystical view of the market. He believed that, whatever happened, the market would adjust (cf. Heffernan, 2012). Hence, he was unable to recognize the significance of what he saw, including over a hundred smaller, but connected, financial crises in the years before the credit crisis.

\section{Hotspur}

Hotspur in Henry IV shows a counterfeit integrity based more in personal psychology rather than ideology. It focuses on perceived harm to reputation and immediate recourse to "satisfaction". Once more this is not a counterfeit integrity based in deception but rather uncritical imitation of what is perceived as integrity, focused in Homeric heroics and honour. As Edmundson (2015) suggests Hotspur cannot take a joke. He interprets all responses as either an insult to himself or support for him as hero.

For Hotspur, the rebel, and son of Northumberland, integrity is focused largely in the sense of standing up for reputation and being prepared to respond immediately to any challenge. The effects of this counterfeit integrity are much the same as Richard II's, involving polarization and denial of responsibility. Henry IV, admires Hotspur's character and his narrative, focused in honesty, transparency and courage, and wishes that perhaps he were his son. ${ }^{2}$ However, in the comparison with Henry V'S view of honour it is clear that Shakespeare does not see it as wholly admirable. Hotspur does not take responsibility for questioning the base of his integrity. His response is determined by his "nature", losing any sense of self-determination, a critical aspect of integrity. It is important to note that, like Richard, Hotspur chooses to do this, that is, though his thinking and actions are determined he is responsible for this. Hence, though neither intended to deceive they had in fact deceived themselves in relation to their social network. The identity at the heart of this is that of the hero, always ready to respond and bring down the other who offends, however powerful. This sense of counterfeit integrity is related in Shakespeare to tragedy. Figures such as Othello or Leontes $(A$ Winter's Tale) have elements that are admirable, but cannot engage either the truth about themselves or the truth of others.

In business there is strong parallel with the Brent Spar case (Entine, 2002). The battle for Brent Spar involved Shell and Greenpeace who disagreed about the environmentally responsible way of decommissioning this offshore oil storage facility. Greenpeace consciously took the role of hero, fighting against the powerful TNC. They saw the proposed sinking of the Brent Spar as environmentally irresponsible.

In the subsequent "battle", Greenpeace managed the publicity such that when the Spar began to be towed off to the deeper sea they boarded, casting this as it a battle of integrity between profit hungry multinational and the NGO who represented the environment. The result was that that Shell backed down under the pressure of intense publicity. It was only later that the Greenpeace action and the data that they based it on were questioned. Shell argued that there was only 53 tonnes of toxic sludge or oil on the Spar. Greenpeace argued that there was over 14,5000 tonnes of toxic rubbish and over 100 tonnes of toxic sludge. An independent study late noted that was between 74 and 100 tonnes of oil on board the Spar, and that the greater part of this could have been removed easily (Entine, 2002). At the heart of the Greenpeace reaction was a strong sense of their heroic identity, and thus the importance of their taking on Shell in a very direct way. The focus on this identity partly accounted for their polarized view of Shell, their lack of awareness of the actual data in the case, and for the avowed determination to react in similar 
ways even after the independent review of the incident (Entine, 2002). This showed limited practice of the first two modes of responsibility. Entine (2002) argues for the importance of NGOs developing dialogue around identity and purpose and about data, representing a much sharper view of integrity.

Once more this suggests counterfeit integrity, without intent to deceive others. The final example from Shakespeare, however, can be characterized as involving deception.

\section{Falstaff}

Falstaff represents the other extreme of counterfeit integrity. He attempts to establish this intentionally, through deception. Falstaff, in Henry IV Parts 1 and 2, develops this through a number of means, including: building a narrative of honour; building a narrative of honesty that attempts to subvert a dominant view of honour; gaining sympathy through rhetoric; and buttressing the narratives with different associations. In the first of these he builds up a narrative of honour, based in supposed success against robbers or on the battlefield. In the latter he claims to have killed Hotspur on the battlefield, who had in fact been already killed by Hal (Henry $\mathrm{V}$ to be). His story is that Hotspur in fact recovered. Falstaff, himself a knight, wants to maintain a narrative of honour and heroism. Despite doubts $\mathrm{Hal}$ accepts and thus reinforces this narrative.

Secondly, key to the narrative of deception is not just Falstaff's ostentatious practice of the Homeric hero but also other likeable, rather than admirable, characteristics. He claims a narrative of plain speaking, and honesty (Henry IV Parts 1, 2, 4), characteristics both associated with integrity. He also claims to be on the side of the ordinary person, and this very much in his major speech about honour,

Can honour set to a leg? no: or an arm? no: or take away the grief of a wound? no. Honour hath no skill in surgery, then? no. What is honour? a word. What is in that word honour? what is that honour? air. A trim reckoning! Who hath it? he that died o' Wednesday. Doth he feel it? no. Doth he hear it? no. 'Tis insensible, then. Yea, to the dead. But will it not live with the living? no. Why? detraction will not suffer it. Therefore I'll none of it. Honour is a mere scutcheon: and so ends my catechism. (Henry IV 1, V 1).

This is a remarkable speech partly because it can be seen as standing up for the ordinary man; there is no working class experience of honour, and Falstaff is in sympathy with that. This can be seen as a critique of the value of honour; further reinforcing a sense of integrity. We can almost see him as a hero for the common man, standing out against Hotspur's view of honour. The speech, of course, is a monologue carefully focused at the audience. Shakespeare is intentionally drawing in the audience to support Falstaff. Similarly, Falstaff, in a role play with Hal, each taking the part of Henry IV, shows off splendid rhetorical devices, aimed at both convincing the king of his integrity but also showing that Falstaff does not, unlike Hotspur, take himself too seriously. In response to the "king's" challenge he rounds off his peroration with,

No, my good lord; banish Peto,

banish Bardolph, banish Poins: but for sweet Jack

Falstaff, kind Jack Falstaff, true Jack Falstaff,

valiant Jack Falstaff, and therefore more valiant,

being, as he is, old Jack Falstaff, banish not him

thy Harry's company, banish not him thy Harry's

company: banish plump Jack, and banish all the world. (Henry

IV, 1: 2, 4)
Characteristic of such counterfeit integrity are attempts then to buttress the heroic narrative with significant relationships. Others then see that the persons and the narrative are supported by the others who, in effect, speak up for the integrity of the person and the narrative. If others support the person then he must have integrity. In Falstaff's case he is buttressed by his tight band of friends in Cheapside. Indeed, he brings his supporters together around his charismatic leadership. Falstaff brooked few questions, batting these off with banter or ad hominem arguments. In this Falstaff generates a strong emotional appeal which superseded critical dialogue.

Much of his time is spent in buttressing his view with the support of Hal, and eventually Henry V (Henry IV 1:3, 4). This is the basis of his relationship to Justice Sly, "demonstrating" his trustworthiness. He is relying on Henry V's support at the end of Henry IV pt. 2 when he races to see the newly crowned king; ultimately, of course, looking for money to pay his debt. He is met, however, with this resounding response,

I know thee not old man, fall to thy prayers'

How ill white hairs become a fool and jester!

I have long dream'd of such a kind of man,

So surfeit-swell'd, so old and so profane;

But, being awaked, I do despise my dream.

Make less thy body hence, and more thy grace. (2 Henry IV, 5.5)

This is one of the most powerful moments in Shakespeare, thought by many to be cruel. Whatever one thinks of Henry V's actions that day, Henry shows here the importance of boundaries, and of making boundaries clear in leadership. Setting boundaries is critical to integrity (Robinson, 2008), not least because it helps to establish identity and enables awareness of the self and the other (Ricoeur, 2000). Without boundaries there is also a loss of meaning.

This reveals the underlying realty of Falstaff s actual motivation and behaviour. In effect, he tries to imitate responsibility, through the accounts he gives of narrative and action and through claiming a critical perspective. This also points to a form of counterfeit integrity focused in "doing the right thing" in order to gain favour with others. In Falstaff's case the attempt to gain favour was an intentional ploy to further his interests. In fact, he practised robbery, desecration of the dead (in stabbing the dead Hotspur), and fraud (using army recruitment to make money). In so doing Falstaff ignores or attempts to blur moral, legal and relational boundaries, and so not surprisingly does not know how to address the new king.

Much the same issues are there in the case of Lance Armstrong, the Olympic and Tour de France cyclist, found guilty of doping in 2012. In that case, however, he was more effective in developing the covering narratives. His end was nonetheless equally cataclysmic. The first element in the Armstrong case was the development of a tightly controlled team culture focused in doping. The USADA (2012) Reasoned Decision document concluded, "He was not just a part of the doping culture, he enforced and re-enforced it. Armstrong's use of drugs was extensive, and the doping programme on his team, designed in large part to benefit Armstrong, was massive and pervasive" (USADA, 2012: 5-6).

The dynamics reflected that of a cult. The classic view of cults (New Religious Movements, NRMs) involves several elements. First, NRMs are controlled by single leaders who have total power over the group, focused in charismatic leadership. Second, NRMs have strong control mechanisms. These range from the "disciple" who is assigned to the new member and ensures his or her total adherence to ideas and practice, to what some critics of NRMs 
have described as mind control techniques. At one level this might be what Barker (1992) refers to as thought stopping-the use of spiritual techniques, such as repeated mantras, that focus on states of mind. Another aspect may be the development of emotional dependence. Hence, cults use "love bombing", initial high care for the new recruit, followed by the threat of expulsion if the recruit does not fulfil set conditions. In Armstrong's case even the racing team officials were involved in disciplining team members including intimidating one of Armstrong's teammates, David Zabriskie, into taking EPO (Erythropoietin). The effect on the team was to increase stress and fear. The aim of such leadership is to infantilize the members of the group, thus diminishing rational autonomy, and the capacity to handle ambiguity. Hence, key to the corruption was the development of culture which centred on a polarized view of the team in relation to the sport and the rest of the world. The fixed purpose of the team was to elevate Armstrong and hence defend him against any external threats. Typically therefore any questions about the team were met with ad hominem arguments. The questioners were out "to get" Armstrong. When federal agent Jeff Novitsky was assigned to investigate the team, Armstrong (Albergotti, 2013) even hired a lobbyist to develop a position against him, which proved unsuccessful. Armstrong was developing then a culture which radically affected how the sporting and wider world was perceived. As Nussbaum (1990) observes, ethics is as much about perception of the world as about moral judgement. All of this radically affected the sense of identity of the team, placing defensiveness above critical questioning of practice.

In addition to these elements of cult dynamic, which disabled any critical agency. Armstrong built up his image. This was, indeed, a triumph of image over integrity, built upon two narratives. The first narrative was of the Homeric hero. Homeric heroism is often characterized as involving a charismatic individual who succeeds against all the odds, including monsters. In Armstrong's case this led precisely to the larger than life image of the man who could conquer any cycling challenge. In his case the absolute value was winning, and all rationality revolved round that. The winning reinforced the heroic image and with that the hero worship. This general adulation further reinforced the pressure on the team to maintain the culture. Members were part of that reflected glory, affirming their worth.

If this were not enough, a second heroic narrative emerged. In 1996 testicular cancer was diagnosed, with advanced secondaries. Armstrong refused radiotherapy because of the effect this might have had on his balance. Writing for Psychology Today in 2012 Robertson suggested that Armstrong's fight with cancer remains both heroic and moral, "he endured regime after gruelling regime of chemotherapy until the exhausted but poisoned cells of his body finally expelled the cancer. Just two years later, in 1998, in a supreme act of physical and moral courage, he started competing again, and in 1999, he won the Tour de France. Doping or no doping, this is the stuff of heroes" (Robertson, 2012).

Robertson goes on to suggest that Armstrong remains a great man, and that all great men are flawed (cf. Windsor, 2015). This is amplified by Windsor (2015) who records Armstrong's doctor arguing that he remains a hero to all cancer patients. The inference is that the victims of much of the fall of Armstrong were in fact cancer patients. This narrative reinforces the heroic image of Armstrong to almost untouchable heights, further reinforcing the pressure on the team. It adds sympathy to admirable heroism.

In addition to the power of the heroic narratives Armstrong built flying buttresses to further support the counterfeit integrity. In particular, he built relationships with media and business which brought in money to the sport, further reinforcing the support of the governing body of cycling. Sponsors also included the US Postal Service and Discovery, who both wanted to be associated with the heroic narratives, but also brought to the table strong value narratives of service and learning, and which further reinforced the heroic narratives. The picture was complete. If integrity involves the re-presentation of the self over time then this reinforced the presentation of an ideal, heroic self, which could not be questioned, demanding unthinking trust.

\section{Henry V}

If we return to Shakespeare, it becomes clear then that the figure of integrity for him is Henry V. Henry continually opens himself, as son, prince and king to critical dialogue, testing his view of himself. He sustains that through holding together multiple dialogues which hold together a plural self (Burkitt, 2008; Hermans, 2012). A good illustration of this is the St Crispin's Day Speech (Henry V 4,3). The speech is not an exercise in rhetorical rabble rousing but is focused on complexity, involving multiple dialogues and narratives, with, among others, God and Henry's dead father (conjuring up Henry's guilt about his relationship with his father and the wider religious guilt about how Richard II's throne was taken), his leaders, his troops (including troops from different parts of Britain), and the enemy. The speech culminates in dialogue with the French Herald who offers to save the lives of Henry's troops through offering him for ransom. This is precisely the issue which Henry's troops were fearful about, leading to an expression of lack of trust in the king. To offer himself for ransom would have questioned the worth of comrades who had been killed earlier in the campaign. Hence, all the troops were there to hear Henry decline the French offer. The dialogue then is focused in values, worth, purpose and identity, involving affective, cognitive and relational elements. As such the dialogue is open and unrehearsed, with Henry prepared to give account at any point, and prepared to wrestle with the affective elements of the complex social environment.

As noted above it is precisely this form of plural dialogue, which embodies integrity. I also suggested earlier that genuine integrity was not about systems thinking or group think, but about how members of an organization can take responsibility for meaning and practice in relation to the meaning and practice of the organization. Henry's integrity reflects exactly that. He enables vision and purpose to be engaged, but through honest dialogue, internal and external. The exercise of dialogue itself develops trust, partly because it demonstrates empathy, and partly because it requires critical challenge, through engaging difference. In moral terms this engages equal respect, freedom and justice. In intellectual terms it engages rationality, intellectual and affective. In psychological terms it engages perceptions of worth. In political terms it engages the imagination, the possibilities of shared responsibility. Such dialogue is precisely what bridges the so called problem of agency and structure, because it recognizes that so called "structure" is built up of relationships and many different narratives.

Underscoring this development is Hal's (Henry V) own development of the meaning of honour. This is a more profound sense of honour than Hotspur or Falstaff and with it a more mature sense of integrity. Integrity is not simply about standing up for principles and maintaining reputation, it is also about an openness to learn from critical challenge, and the importance of practical wisdom, knowing when to make a response and knowing that the purpose has to be greater than simply "satisfying" honour. This takes us to a more thought through Renaissance view of honour centred in humanity and in balance, not in the narrow identity of the leader. Falstaff might legitimately challenge the latter, with integrity individualized, but the former challenges Falstaff. It is ultimately this sense of shared honour which provides the basis for a united vision before Agincourt, but one that feeds 
into narratives of home and community as well as army life, with all engaging plural narratives.

This brings us back to the dichotomy, set up by Audi and Murphy (2006), between moral content and process. The two are connected by the practice of responsibility and related virtues. Critical agency, accountability and creative responsibility are evidenced through ongoing dialogue and where there is no evidence of that dialogue there is danger of counterfeit integrity. This can also extend to a systems response to corruption that is, one focused in regulation but not in the development of responsibility. This can have the effect of discouraging the practice of dialogue and professional judgment (cf. Goodpaster, 2007). The focus on systems control of corruption then can lead to "crowding out" the virtues (Moore, 2012). As Eliot put it,

\section{They try to escape}

From the darkness outside and within

By dreaming of systems so perfect that no one will need to be good. (Eliot, 2004: 158).

Ironically, the rise of systems thinking is often associated with the practice of accountability. However, the practice of accountability without critical agency can precisely lead to instrumental rationality and isomorphism (Thompson and Bevan, 2013).

\section{Conclusion}

This article has suggested that counterfeit integrity can involve unintended or intended deception. Key to the first of these is reliance on ideology or identity, which is not subject to critical scrutiny or the challenge of dialogue. Key to the second is careful building of a narrative which is emotionally powerful, and which intentionally runs counter to practice. This builds a perspective that is difficult to criticize, and which draws in different organizations and persons to become, in effect, part of the counterfeit integrity. Emerging from this is the suggestion that integrity has to involve the practice of all modes of responsibility individually and organizationally, and that this is focused in complexity and dialogue.

\section{Notes}

1 Hence, in Hamlet, Polonius's aphorism to his son, 'and, above all to thine own self be true' (Act 1 Scene 3) reflects not Shakespeare's belief in a single self, but Polonius's lack of awareness about the complex self. It is precisely such as complex self that Hamlet inhabits.

2 In Hotspur there are strong elements of celebrity which Marshall notes relates directly to persona (see Marshall and Barbour 2015).

\section{References}

Albergotti R (2013) Armstrong Lobbying Targeted Investigator. Wall Street Journal. 1 July

Arendt H (1991) Organized guilt and universal responsibility. In: May L and Hoffman $\mathrm{H}$ (eds). Collective Responsibility: Five Decades of Debate in Theoretical and Applied Ethics. Savage, Rowbottom and Littlefield: New York.

Audi R and Murphy P (2006) The many faces of integrity. Business Ethics Quarterly; 16 (1): 3-21.

Bakhtin M (1984) The Dialogic Imagination: Four Essays. University of Texas: Austin, TX.

Barker E (1992) New Religious Movements. HMSO: London.

Bauman D (2013) Leadership and the three faces of integrity. The Leadership Quarterly; 24 (2): 414-426.

Bauman Z (1989) Modernity and the Holocaust. Polity: London.

Beebe J and Rosen D (2005) Integrity in Depth. Texas A\&M University Press: Austin, TX.

Berlin I (1968) Two Concepts of Liberty. In: Quinton A (ed). Political Philosophy. Penguin: London, pp 141-155.

Brown M (2005) Corporate Integrity. Cambridge University Press: Cambridge, UK. Burkitt I (2008) Social Selves: Theories of Self and Society. Sage: London.
Burleigh M (2011) Moral Combat. Harper: London.

Calhoun C (1995) Standing for something. Journal of Philosophy; XCII (5): 227-238.

Callender J (2010) Free will and Responsibility. Oxford University Press: Oxford.

Cohen S (2001) States of Denial: Knowing About Atrocities and Suffering. Polity Press: London.

Cooper-White P (2007) Many Voices. Fortress: Minneapolis, MN.

Cottingham J (2010) Integrity and fragmentation. Journal of Applied Philosophy; 27 (1): $2-14$.

Cox D, La Caze M and Levine M (1999) Should we strive for integrity? Journal of Value Inquiry; 33 (4): 519-530.

Curzer H (2014) Aristotle and the Virtues. Oxford University Press: Oxford.

Edmundson H (2015) Why Hotspur can't take a joke: Temperament and leadership in Shakespeare's Henry IV. Public Integrity, Part 1; 17 (3): 247-263. Eliot TS (2004) Complete Poems and Plays. Faber and Faber: London.

Entine J (2002) Shell, Greenpeace and Brent Spar; the politics of dialogue. In: Megone $\mathrm{C}$ and Robinson S (eds). Case Histories in Business Ethics. Routledge: London.

Fawkes J (2014) Public Relations Ethics and Professionalism: The Shadow of Excellence. Routledge: London.

Festinger L (1962) Cognitive dissonance. Scientific American; 207 (4): 93-107.

Freeman M (2015) Rewriting the Self. Routledge: London.

Flavell J (1987) Speculation about the nature and development of metacognition. In: Weinert $\mathrm{F}$ and Kluwe $\mathrm{R}$ (eds). Metacognition, Motivation, and Understanding. Lawrence Erlbau: Hillsdale, NJ, pp 21-29.

Forrest A and O'Rourke R (2015) The Modern Slavery Bill: A Step in the Right Direction, Huffington Post, 4 June.

Frankfurt H (1971) Freedom of the will and the concept of a person. Journal of Philosophy; 68 (2): 5-20.

Gergely G and Csibra G (2005) The social construction of the cultural mind: Imitative learning as a mechanism of human pedagogy. Interaction Studies; 6 (3): 463-481.

Goffman E (1956) The Presentation of Self in Everyday Life. Doubleday: New York. Goodpaster KE (2007) Conscience and Corporate Culture. Blackwell: London.

Halfon M (1989) Integrity: A Philosophical Inquiry. Temple University Press: Philadelphia, PA.

Heffernan M (2012) Wilful Blindness. Simon and Schuster: London.

Hermans H (2012) Between Dreaming and Recognition seeking: The Emergence of Dialogical Self Theory. Maryland: University Press of America: Lanham, MD.

Homans P (1995) Jung in Context. University of Chicago Press: Chicago, IL.

Jonas H (1984) The Imperative of Responsibility. Chicago University Press: Chicago, IL.

Jung CG (1938) Psychology and Religion. Yale University Press: New Haven, CT. Jung CG (1953) Two Essays on Analytical Psychology. Routledge and Kegan Paul: London.

Khurana R and Nohria N (2008) It's time to make management a true profession. Harvard Business Review; 86 (10): 70-77.

Koehn D (2005) Rethinking Feminist Ethics. Routledge: London.

Korsgaard C (2009) Self-Constitution: Agency, Identity, and Integrity. Oxford University Press: Oxford.

Lovejoy A (1964) The Great Chain of Being. Doubleday: New York.

Marshall PD and Barbour K (2015) Making intellectual room for Persona studies: A new consciousness and a shifted perspective. Persona Studies; 1 (1): 1-12.

Mason M (2001) The ethics of integrity: Educational values beyond postmodern ethics. Journal of Philosophy of Education; 35 (1): 47-69.

Miller W (ed) (2003) Integrating Spirituality into Treatment. American Psychological Association: Washington DC.

Moore G (2012) The virtue of governance, the governance of virtue. Business Ethics Quarterly; 22 (2): 293-318.

Nussbaum M (1990) Love's Knowledge: Essays on Philosophy and Literature. Oxford University Press: New York.

Palanski M and Yammarino F (2007) Integrity and leadership: Clearing the conceptual confusion. European Management Journal; 25 (1): 171-184.

Pianalto M (2012) Integrity and struggle. Philosophia; 40 (2): 319-336.

Rand A (1992) Atlas Shrugged; (35th anniversary edition). Dutton: New York.

Rawls J (1972) A Theory of Justice. Clarendon Press: Oxford.

Ricoeur P (1987) Time and Narrative III. University of Chicago Press: Chicago, IL.

Ricoeur P (2000) The Concept of Responsibility: An Essay in Semantic Analysis in The Just; trans. D Pellauer. The University of Chicago Press: Chicago, IL.

Robertson W (2012) The Winner Effect: Why Lance Armstrong Is Still a Hero, https://www.psychologytoday.com/blog/the-winner-effect/201210/why-lancearmstrong-is-still-hero, Accessed 5 April 2016.

Robinson S (2008) Spirituality, Ethics and Care. Jessica Kingsley: London.

Robinson S (2009) The nature of responsibility in a professional setting. Journal of Business Ethics; 88 (1): 11-19.

Robinson S (2016) Integrity and the Practice of Business. Palgrave Macmillan: London.

Robinson S and Smith J (2014) Co-Charismatic Leadership. Peter Lang: Oxford.

Scherkoske G (2013) Integrity and the Virtues of Reason: Leading a Convincing Life. Cambridge University Press: Cambridge, UK. 
Sidorkin A (1999) Beyond Discourse: Education, the Self and Dialogue. State University of New York Press: Albany, NY.

Solomon R (1984) Ethics and Excellence. Oxford University Press: Oxford.

Solomon R (2007) True To Our Feelings. Oxford University Press: Oxford.

Taylor C (1989) Sources of the Self. Cambridge University Press: Cambridge,

UK.

Thompson M and Bevan D (2013) Wise Management in Organisational Complexity. Palgrave Macmillan: London.

USADA. (2012) Report on proceedings under the world anti-doping code and the USADA protocol united states anti-doping agency, Claimant, v. Lance Armstrong, Respondent. Reasoned Decision, https://d3epuodzu3wuis.cloud front.net/ReasonedDecision.pdf, accessed 22 May 2016.

van der Ven J (1998) Formation of the Moral Self. Eerdmans: Grand Rapids, MI. Williams B (1973) Integrity. In: Smart JJC and Williams B (eds). Utilitarianism: For and Against. Cambridge University Press: New York, pp 108-117.

Windsor R (2015) Armstrong doctor: Lance remains a hero to every cancer patient', Cycling Weekly, http://www.cyclingweekly.co.uk/news/latest-news/arm strong-doctor-lance-remains-a-hero-to-every-cancer-patient-189625\#YXTgkA K3A8ygfLUT.99, accessed 22 May 2016.

\section{Data availability}

Data availability not applicable to this article as no datasets were generated or analysed.

\section{Additional information}

Competing interests: The authors declare no competing financial interests.

Reprints and permission information is available at http://www.palgrave-journals.com/ pal/authors/rights_and_permissions.html

How to cite this article: Robinson S (2016) Integrity and its counterfeits: Shakespeare's Henriad. Palgrave Communications. 2:16068 doi: 10.1057/palcomms.2016.68.

\section{(c) (i)}

This work is licensed under a Creative Commons Attribution 4.0 International License. The images or other third party material in this article are included in the article's Creative Commons license, unless indicated otherwise in the credit line; if the material is not included under the Creative Commons license, users will need to obtain permission from the license holder to reproduce the material To view a copy of this license, visit http://creativecommons.org/licenses/by/4.0/ 